\title{
On the Critical Speed, Supercritical Bifurcation, and Stability Problems of Certain Type of High-Speed Rail Vehicle
}

\author{
Hao Dong' and Qunsheng Wang ${ }^{2}$ \\ ${ }^{1}$ Department of Mechanical Engineering, Chengdu University, Chengdu, China \\ ${ }^{2}$ Traction Power State Key Laboratory, Southwest Jiaotong University, Chengdu, China \\ Correspondence should be addressed to Hao Dong; fusiji@my.swjtu.edu.cn
}

Received 8 February 2017; Revised 3 May 2017; Accepted 18 June 2017; Published 19 July 2017

Academic Editor: Longjun Dong

Copyright ( 2017 Hao Dong and Qunsheng Wang. This is an open access article distributed under the Creative Commons Attribution License, which permits unrestricted use, distribution, and reproduction in any medium, provided the original work is properly cited.

\begin{abstract}
Recently, Chinese engineers have proposed a simple way to find the vehicles' critical speed, which is similar to the ramping method. In this article, through an example of vehicle of supercritical properties, it is proved that the new easier way is not scientifically justified and should not be used in engineering practice. In addition, the ramping way also yields inaccurate critical speed. Then one abnormal vibration phenomenon which appears on Beijing-Shanghai high-speed line is studied. The results demonstrate that it is car body hunting but not bogie hunting. Finally, through the computation and comparison of the lateral ride indices under different conditions, one stability problem about stochastic limit cycle banding is tentatively discussed.
\end{abstract}

\section{Introduction}

The railway vehicle stability problem has been investigated for years. Since the nonlinear bifurcation theory is utilized in solving nonlinear vehicle problems [1-3], the study on the calculation of critical speed gets a great deal of achievements $[4,5]$. The right way for calculating the critical speed refers to the path following (continuation) or ramping method [6]. Besides this, the typically wrong way is also discussed. In addition, in some manufacturer and research institutes [7], especially in China with its booming high-speed vehicle demand, the third simple way based on the continuation or ramping method is proposed and generally used. That method is only calculating the stable periodical solution, similar to ramping way, and not calculating the unstable limit cycle. Specifically, first the method involves yielding the large amplitude stable limit cycle, then decreasing speed with small stepsize to find smaller amplitude stable limit cycle, and decreasing speed stepwise until converging to the trivial solution (the trivial solution here is zero solution (as shown in Figure 3), which is different from periodical solution (as shown in Figure 11)). The critical speed is the corresponding value.
However, the three ways for calculating critical speed have advantages and disadvantages. The continuation method is undoubtedly rigorous but time-wasting. The other two ways are fast but existing problems, one of which may be overshooting the bifurcation point [4]. Moreover, decreasing speed is a necessary step in both the ramping and the third method, as we know; we must determine the speed which makes the periodical solution converge to the trivial one. That is another problem where we usually calculate the inaccurate critical speed especially for the supercritical Hopf bifurcation type.

Regarding CRH380B, one typical supercritical Hopf bifurcation type of high-speed vehicle in China, its dynamic models are depicted in Figure 1. The examples of bifurcation diagrams of CRH380B on straight lines and its special conditions (such as one fault condition) are used to give further instruction as shown in Figure 2.

When the ramping or the third method is used, it always yields the critical speed of about $300 \sim 350 \mathrm{~km} / \mathrm{h}$, even $400 \mathrm{~km} / \mathrm{h}$. This is because, with certain speed when we solve the vehicle dynamical system, we must ensure whether the result converges to the trivial solution (the constant zero), but sometimes, the convergent rate is very slow as shown 


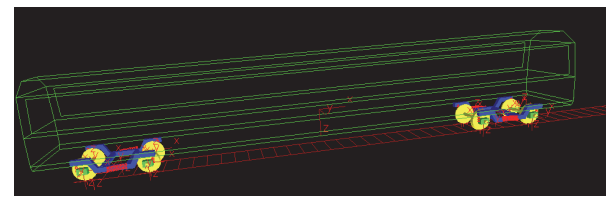

FIgURE 1: Dynamic model for CRH380B.

in Figure 3 obtained by Simpack simulation. Obviously, the result does not converge to 0 within 20 seconds.

Especially in engineering applications, the computation is huge. Therefore, some researchers propose a simple way, which depends on the small vibration amplitude $[8,9]$. If the result converges so slowly for some reasons (algorithm, singularity of model, correctness or complexity of model, etc.), they set a threshold of amplitude for the limit cycle to determine the critical speed. To be exact, the threshold is about $0.5 \mathrm{~mm}$ or even $1 \mathrm{~mm}$ as shown in Figure 2(b). Hence the last step when using ramping or the third method is that if the result does not converge to the trivial solution but its amplitude is smaller than $0.5 \mathrm{~mm}$, they regard the speed as the critical one. To distinguish it from the critical speed $V_{\mathrm{cr}}$ in theory, we define the above-mentioned speed which is used in engineering as $V_{E}$. In most subcritical Hopf bifurcation situations, $V_{E}$ undoubtedly equals $V_{\mathrm{cr}}$. But however, this is not true in the case of some supercritical bifurcation as shown in Figure 2, which leads to error estimation of $V_{\mathrm{cr}}$ for nearly one hundred kilometers per hour. So when $V_{E}$ is used instead of $V_{\mathrm{cr}}$, we must pay attention to the situation $V_{\mathrm{cr}}=$ Hopf bifurcation point (linear critical speed).

The main work of this paper involves the critical speed of supercritical Hopf bifurcation of types CRH380B (Prototype of ICE3) and some stability problems.

\section{The Disadvantage of $V_{E}$}

As we know, CRH3's prototype is the ICE3 train. China's railway authorities modify it as a higher operation speed train, CRH380B, with structure or parameters optimization. One of the most important parameters is the bogie primary radial positioning (location node of box arm) stiffness $k_{p x}$. Figure 4 shows the influence of that on $V_{E}$ and $V_{\mathrm{cr}}$.

From Figure 4, it can be seen that the laws of $V_{E}$ and $V_{\text {cr }}$ are different and even opposite. Exactly, with the stiffness becoming large, $V_{E}$ decreases while $V_{\mathrm{cr}}$ increases. Particularly, the laws of $V_{E}$ are believed to be correct according to some research reports $[10,11]$. As a result, considering that CRH380B is designed to obtain higher operation speed $(350-380 \mathrm{~km} / \mathrm{h})$ than CRH3 based on CRH3's structure or parameters, if $V_{E}$ is used instead of $V_{\mathrm{cr}}$, it is unscientific and may be dangerous.

To provide further discussion on $V_{E}$ and $V_{\text {cr }}$ and to prove the inaccuracy of $V_{E}$, we choose two cases.

Case 1. $k_{p x}=30 \mathrm{MN} / \mathrm{m}, V_{\mathrm{cr}}=370 \mathrm{~km} / \mathrm{h}<V_{\text {Op }}, V_{E}=510 \mathrm{~km} / \mathrm{h}$ $>V_{\mathrm{Op}}$.

Case 2. $k_{p x}=115 \mathrm{MN} / \mathrm{m}, V_{\mathrm{cr}}=V_{E}=386 \mathrm{~km} / \mathrm{h}>V_{\mathrm{Op}}$.
TABLE 1: Eigenvalues for $k_{p x}=30 \mathrm{MN} / \mathrm{m}$.

\begin{tabular}{lc}
\hline Nat. damping & Frequency $(\mathrm{Hz})$ \\
\hline 1 & 0.2325 \\
1 & 0.7672 \\
0.0285 & 1.0079 \\
0.0606 & 1.8823 \\
0.0561 & 1.9632 \\
0.0404 & 2.0079 \\
0.0731 & 2.3198 \\
0.9899 & 2.5590 \\
0.9831 & 3.3193 \\
0.3636 & 3.4589 \\
0.4235 & 3.9598 \\
$\mathbf{- 0 . 0 0 4 3}$ & $\mathbf{7 . 0 0 5 5}$ \\
$\mathbf{- 0 . 0 0 8 6}$ & $\mathbf{7 . 0 2 5 3}$ \\
0.7082 & 9.3246 \\
0.7076 & 9.3303 \\
\hline
\end{tabular}

$V_{\text {Op }}=380 \mathrm{~km} / \mathrm{h}$ is the operation speed.

Now, the eigenvalues and eigenvectors of CRH380B vehicle are calculated by Simpack software.

Case 1. The results are depicted in Table 1.

In Table 1, the left column denotes the nature damping. This can be simply understood as corresponding eigenvalues multiplied by $-C$ ( $C$ is a positive constant). The right side denotes the eigenfrequency. So, if a negative value of nature damping appears, similar to the positive eigenvalues, the linearized system of CRH380B is unstable. In addition, from Figure 2, because $V_{\mathrm{cr}}=V_{\text {lin-cr }}=V_{\text {non-cr }}=$ Hopf, the nonlinear system of CRH380B is also unstable.

In Table 1, there are a pair of negative values of nature damping and its corresponding frequencies of about $7 \mathrm{~Hz}$. The corresponding eigenvectors are shown in Figure 5.

From Table 1 and Figure 5, it can be seen that the rear bogie loses stability at this operation speed with frequency of about $7 \mathrm{~Hz}$ (the other negative value of nature damping corresponds to the front bogie). These imply that, in the case of $k_{p x}=30 \mathrm{MN} / \mathrm{m}$, the critical speed is undoubtedly less than $380 \mathrm{~km} / \mathrm{h}$ and $V_{E}=510 \mathrm{~km} / \mathrm{h}>380 \mathrm{~km} / \mathrm{h}$ is not safe.

Case 2. The results are depicted in Table 2.

There is no negative value in the left column in Table 2, which means the critical speed is greater than $380 \mathrm{~km} / \mathrm{h}$.

Combined with the analysis of Cases 1 and 2, $V_{E}$ is unscientific and cannot be used in vehicle design.

\section{One Possible Reason for the Difference}

From Figure 4, it can be seen that

$$
\begin{aligned}
& V_{\mathrm{cr}}<V_{E}, \quad \text { when } k_{p x}<115 \mathrm{MN} / \mathrm{m} \\
& V_{\mathrm{cr}}>V_{E}, \quad \text { when } k_{p x}>115 \mathrm{MN} / \mathrm{m} .
\end{aligned}
$$




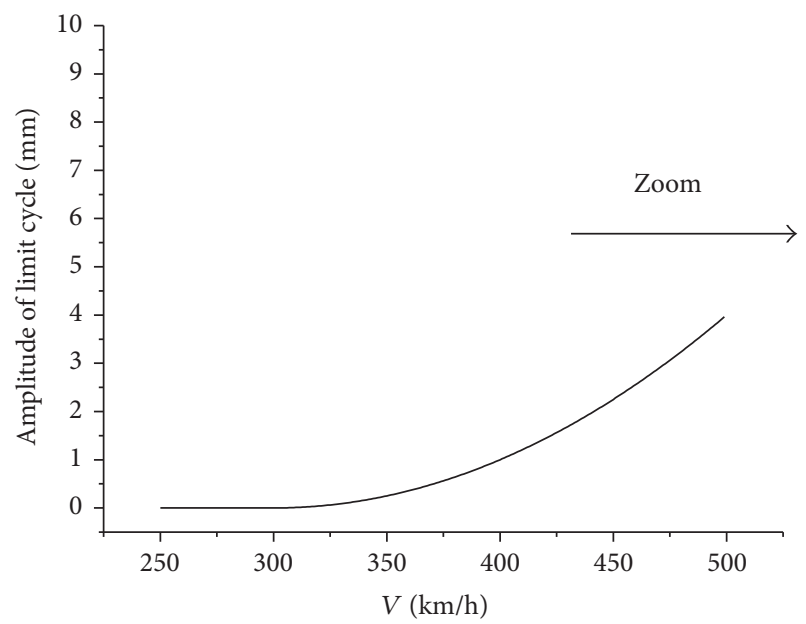

(a)

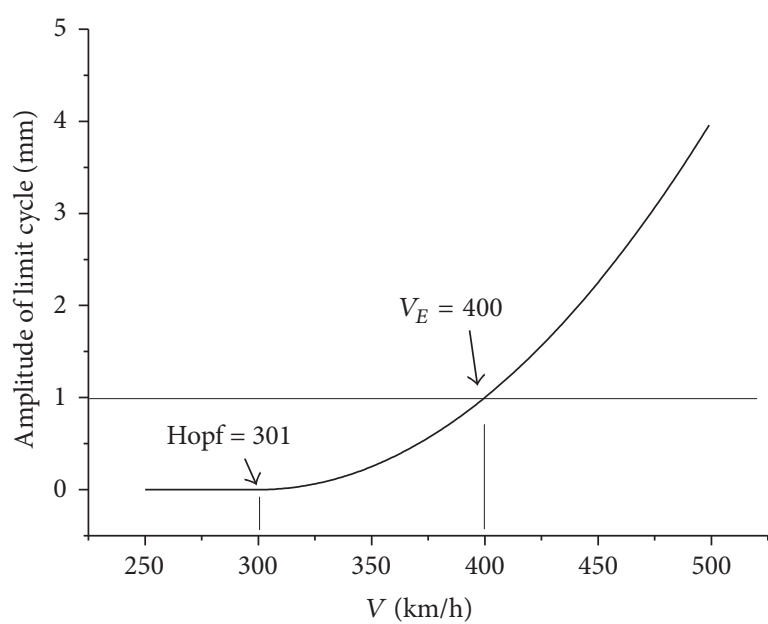

(b)

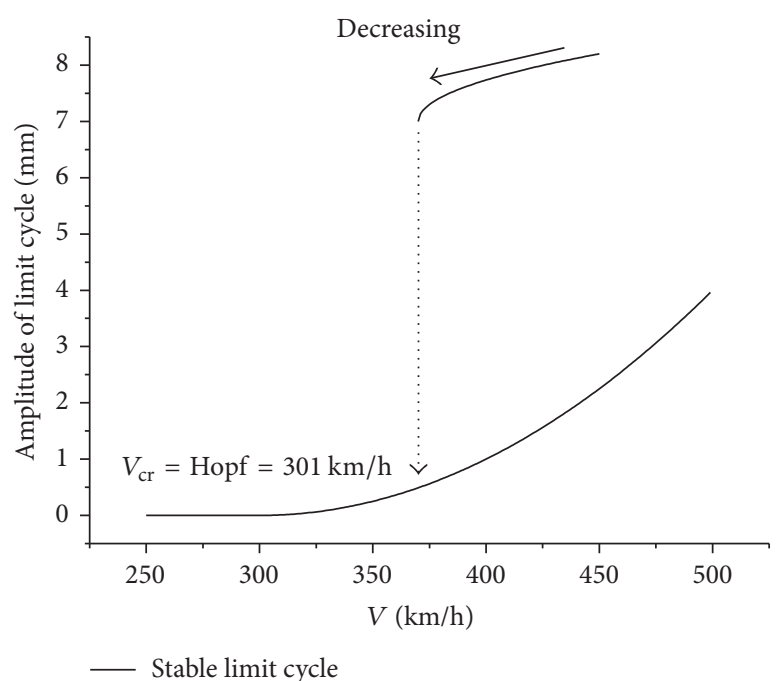

(c)

FIGURE 2: Lateral bifurcation of CRH380B's wheelset ((a) and (b): normal conditions; (c): special conditions).

Should it be doubted that some limit cycles such as those in Figure 3 are not "real" by macroscopic observation? It may be caused by the algorithm accuracy.

Now, set parameters $k_{p x}=120 \mathrm{MN} / \mathrm{m}$ (designing default) and the vehicle speed as $370 \mathrm{~km} / \mathrm{h}<V_{\mathrm{cr}}=380 \mathrm{~km} / \mathrm{h}$ according to Figure 4. The solving algorithm is SODASRT [12-14], and its accuracy is, respectively, $10^{-5}$ for Case A and $10^{-6}$ for Case B. The initial condition is depicted in Figure 6, the detail of which is the lateral track irregularities in the first 3 seconds and no irregularity afterwards. The response result is depicted in Figure 7.

From Figure 7, it is unimaginable that solving the same equation and parameters yields different results if we ignore the algorithm accuracy. Specifically, Case A converges to the small amplitude limit cycle and Case B converges to the trivial solution. However the vehicle speed is $370 \mathrm{~km} / \mathrm{h}<V_{\text {cr. }}$. So Case B is correct. This situation is common in engineering because we usually set the accuracy as default but not higher precision in order to solve the system faster. As we know, the higher precision may make the solving process very slow. In engineering, it is usually ignored.

According to the above, if we use $V_{E}$ instead of $V_{c r}$, the error may also be caused by algorithm accuracy. Furthermore looking at Figure 2, the interval between $V_{E}$ and $V_{\text {cr }}$ may be one hundred kilometers per hour and the algorithm accuracy's effect may exist. Therefore $V_{E}$, which is obtained by macroscopic observation based on simple bifurcation analysis, is unreliable.

There is a great deal of the research about the influence of algorithm accuracy on the response of mechanical systems, especially in aircraft [15]. It is possible to apply the same research technique to rail vehicles.

\section{One Problem about Stability}

According to the two-year test for $\mathrm{CRH} 3$ operating on the Beijing-Shanghai high-speed line, an abnormal vibration phenomenon of car body appears on some sections, which 
TABLE 2: Eigenvalues for $k_{p x}=115 \mathrm{MN} / \mathrm{m}$.

\begin{tabular}{lc}
\hline Nat. damping & Frequency $(\mathrm{Hz})$ \\
\hline 0.0280 & 1.0763 \\
0.0547 & 1.9598 \\
0.0470 & 2.0473 \\
0.0347 & 2.0604 \\
0.0570 & 2.5242 \\
0.3682 & 3.4584 \\
0.4274 & 3.9547 \\
0.9621 & 4.4891 \\
0.9555 & 4.8816 \\
0.0075 & 6.6075 \\
0.0037 & 6.6300 \\
0.6168 & 11.571 \\
0.6162 & 11.576 \\
0.2763 & 11.991 \\
0.2725 & 12.0062 \\
0.4537 & 15.7025 \\
\hline
\end{tabular}

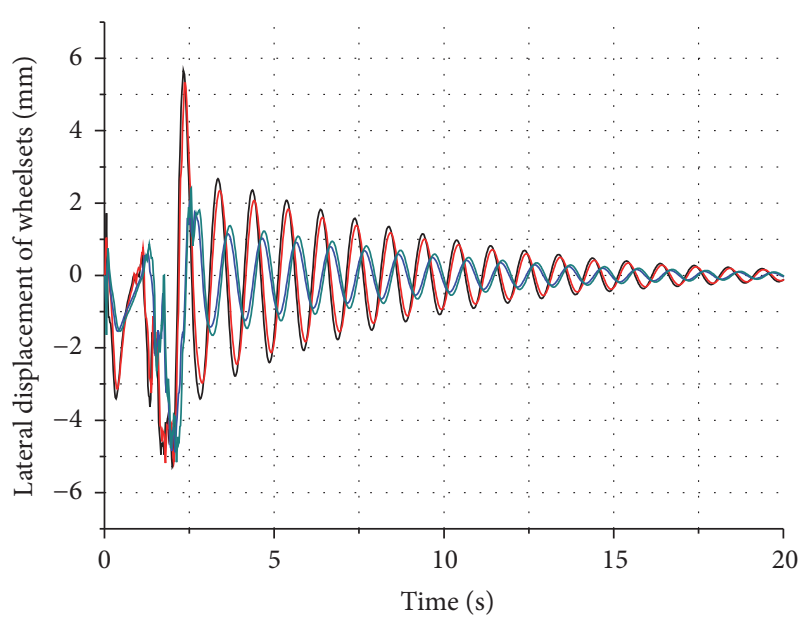

FIGURE 3: Slow convergence rates for four wheelsets of one vehicle.

makes passengers feel uncomfortable and complain to the railway authorities. The test results for car body are depicted in Figure 8.

In the beginning, this phenomenon was regarded as what was coming from bogie hunting transmission, although the bogie vibration has the same frequencies (about 1.6-1.8 Hz) and modes. However, the frequencies of about $1.6-1.8 \mathrm{~Hz}$ are far from hunting ones which are around $7 \mathrm{~Hz}$ as shown in Table 1. Therefore, we make further analysis by Simpack simulation for the whole vehicle. Firstly, because this vibration phenomenon only exists on special sections, we doubt that the gauge variation was the key. The influence of gauge variation on critical speed is depicted in Figure 9. Point $P$ corresponds to the nominal track gauge. Here in CRH380B vehicle, for its supercritical Hopf bifurcation type as shown in Figure 2(b), $V_{\text {lin-cr }}=V_{\text {non-cr }}=$ Hopf bifurcation point.

From Figure 9, whenever the gauge is smaller than $1430 \mathrm{~mm}$ or greater than $1442 \mathrm{~mm}$, the critical speed is

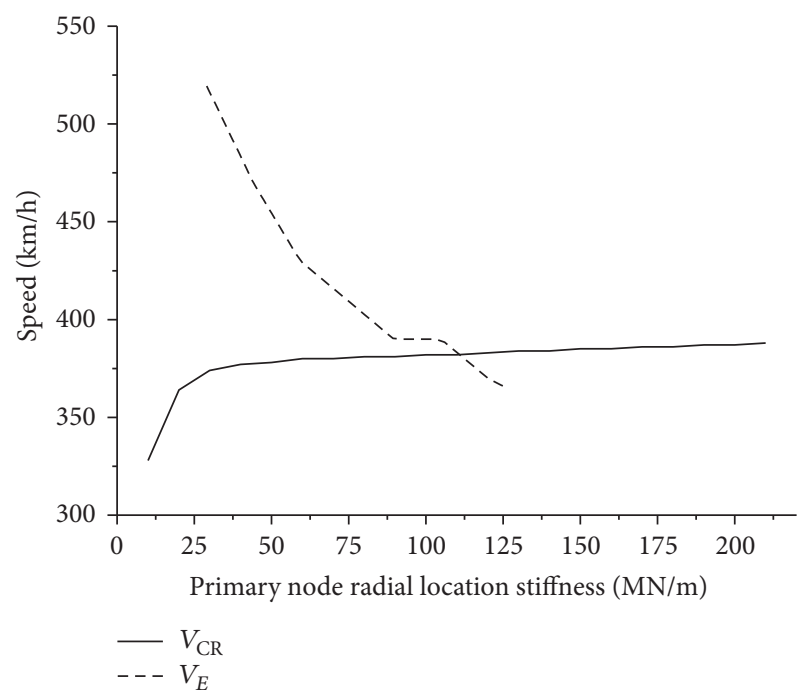

FIGURE 4: Influence of primary location stiffness on $V_{E}$ and $V_{\text {cr }}\left(V_{\text {cr }}\right.$ $=V_{\text {lin-cr }}=V_{\text {non-cr }}=$ Hopf, where $V_{\text {lin-cr }}$ is the linear critical speed and $V_{\text {non-cr }}$ is the nonlinear one).

smaller than $300 \mathrm{~km} / \mathrm{h}$. In particular when the gauge increases to $1444 \mathrm{~mm}$, the critical speed is very low at around $150 \mathrm{~km} / \mathrm{h}$, which cannot guarantee safety. Moreover, the details of the influence of gauge on stability were studied by Zboiński and Dusza [16].

Secondly, assume the gauge increases to $1450 \mathrm{~mm}$ and the operation speed is also $300 \mathrm{~km} / \mathrm{h}$. The results for the whole vehicle simulation are shown in Figure 10.

In Figure 10, it is obvious that the simulation results of wheelset, bogie, and car body have the same resonance frequency. Specifically, the first two have nearly the same vibration wave shape for the large positioning stiffness (primary node stiffness $=120 \mathrm{MN} / \mathrm{m}$ ). Besides the frequency is about $1.6 \mathrm{~Hz}$, similar to what is shown in Figure 7. Although the wave shapes look like bogie hunting, the frequency is far from that. According to Figure 8, we know that this result corresponds to the instability case because $V_{\text {cr }}<300 \mathrm{~km} / \mathrm{h}$. Why do the results look like bogie hunting and why are the values of frequency far from the hunting ones? Then, the eigenfrequency and eigenvectors are calculated as shown in Table 3.

From Table 3 , the vehicle has two negative nature damping values which correspond to positive eigenvalues and the eigenfrequencies are 1.6 and $1.8 \mathrm{~Hz}$. Therefore, the simulation analysis results correspond to the test results as shown in Figure 8 . Furthermore, the unstable eigen modal vectors are depicted in Figure 11.

Now it is obvious that, from Figure $11(\mathrm{a})$, the $1.6 \mathrm{~Hz}$ vibration corresponds to the car body yaw motion and the $1.8 \mathrm{~Hz}$ vibration corresponds to the car body rolling motion. Therefore, the abnormal vibration which makes passengers uncomfortable is car body hunting but not bogie hunting. Also this phenomenon only appears on some special sections. So according to Figure 9, in the author's opinion, it may be caused by gauge variation on some part of the whole BeijingShanghai high-speed line. 


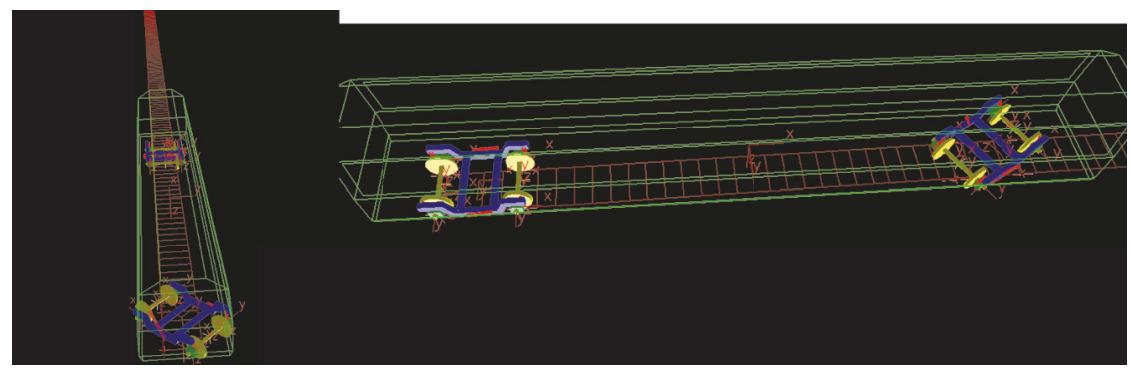

Rear bogie

Front bogie

FIGURE 5: Eigenvectors for the unstable bogie (solved by Simpack).

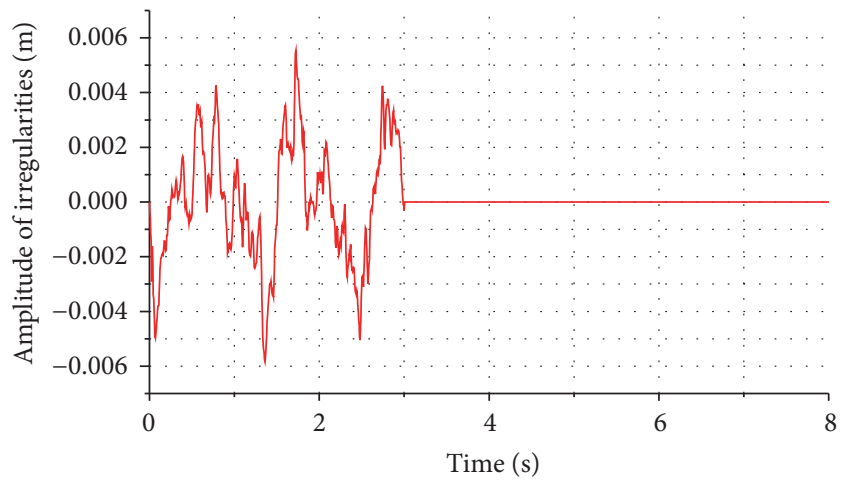

FIGURE 6: Initial condition: lateral track irregularities with the first 3 seconds.

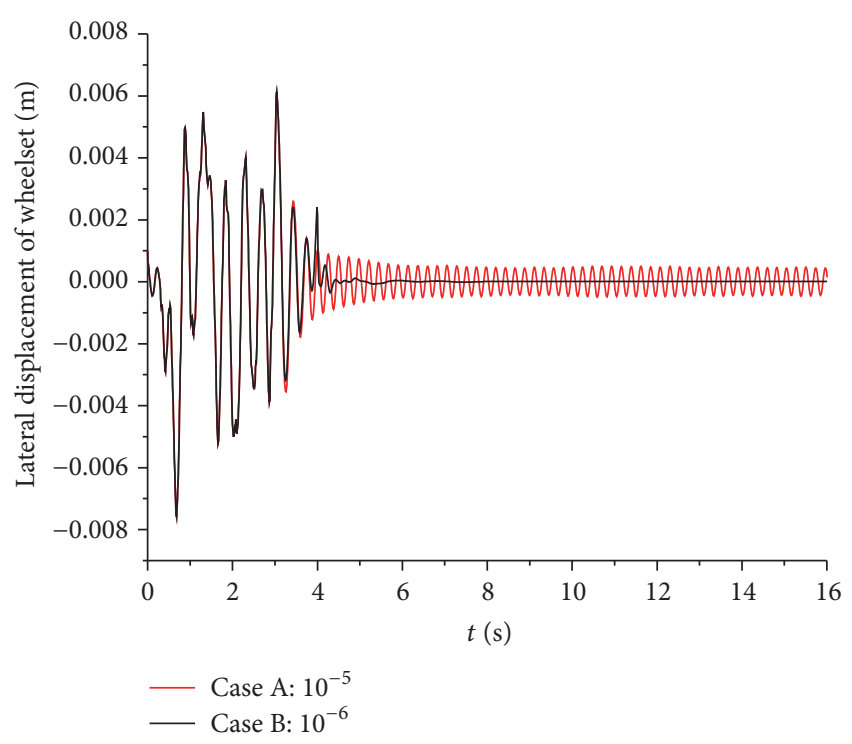

FIGURE 7: Response for different algorithm accuracy (first wheelset on straight line).

\section{One Extended and Unknown Problem}

Perhaps the following problem exists in vehicle dynamic simulation. Two types of vehicles are running in different conditions as follows. Vehicle A behaves as a subcritical Hopf bifurcation, while vehicle B behaves as a supercritical one.
TABLE 3: Eigenvalues for gauge $=1450 \mathrm{~mm}$ and speed $=300 \mathrm{~km} / \mathrm{h}$.

\begin{tabular}{lc}
\hline Nat. damping & Frequency $(\mathrm{Hz})$ \\
\hline 0.0482 & 0.8972 \\
$\mathbf{- 0 . 0 3 3 1}$ & $\mathbf{1 . 6 0 3 5}$ \\
$\mathbf{- 0 . 1 9 1 9}$ & $\mathbf{1 . 8 3 6 3}$ \\
0.2934 & 2.0367 \\
0.0471 & 2.0457 \\
0.4043 & 2.0827 \\
0.0571 & 2.5222 \\
0.3675 & 3.4603 \\
0.4269 & 3.9571 \\
0.8586 & 9.9214 \\
0.8541 & 10.140 \\
0.6176 & 11.553 \\
0.6169 & 11.559 \\
0.2766 & 11.982 \\
0.2727 & 12.057 \\
0.4045 & 14.172 \\
\hline
\end{tabular}

Case 1. Vehicle A is running below its critical speed but is excited by track irregularity (both lateral and vertical). Therefore, the time domain response is random.

Case 2. Vehicle A is running above its critical speed with initial value as shown in Figure 6. Its time domain response is periodical solution.

Case 3. The same vehicle is also running at the same speed as in Case 2 and also is excited by track irregularity as Case 1. Its time domain response behaves like random signal adding to periodical solution.

The results of the three cases are depicted in Figure 12.

Now, the lateral ride indices for the three cases are calculated as shown in Table 4. The lower value demonstrates the higher ride quality (the ride index is similar to comfort index. The former is made by Chinese standard GB559985 and contains separate lateral and vertical computation processes [17], while the latter refers to UIC 513 code [18]).

The results shown in Table 4 seem to be reasonable because the vibration level gets worse.

However, the following cases are not the same. 


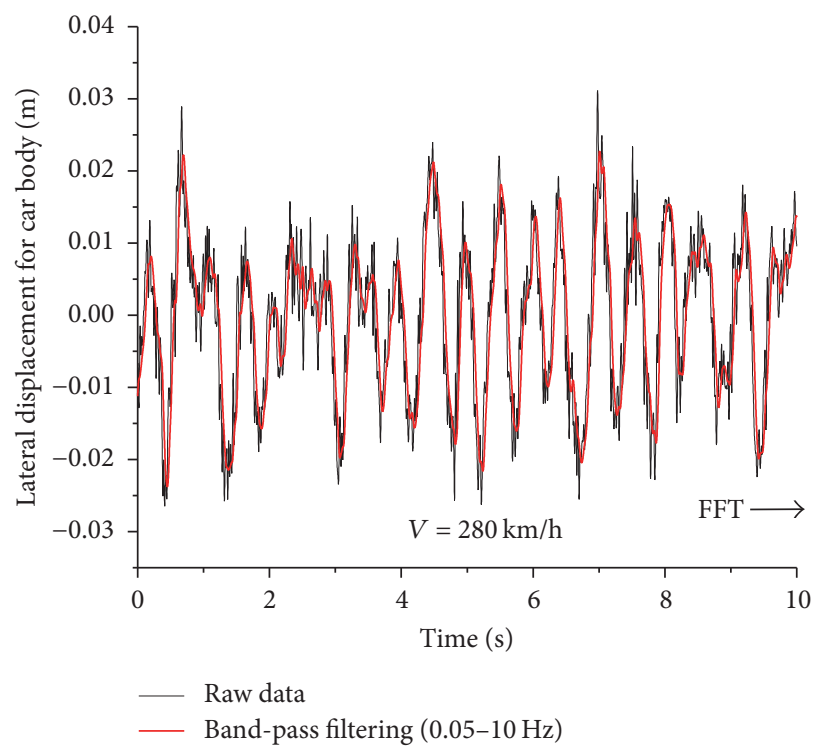

(a)

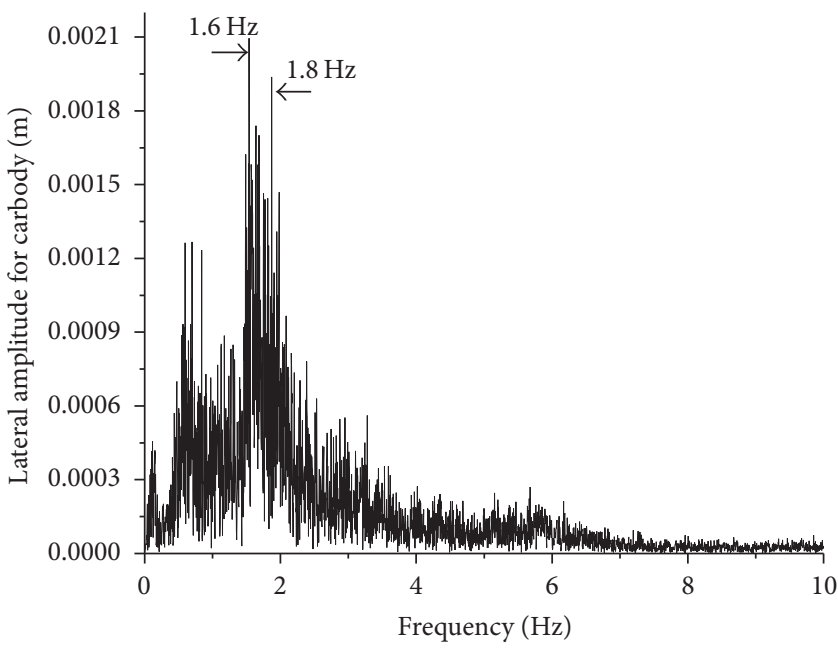

(b)

FIGURE 8: Response for vehicle vibration ((a): time domain; (b): frequency domain).

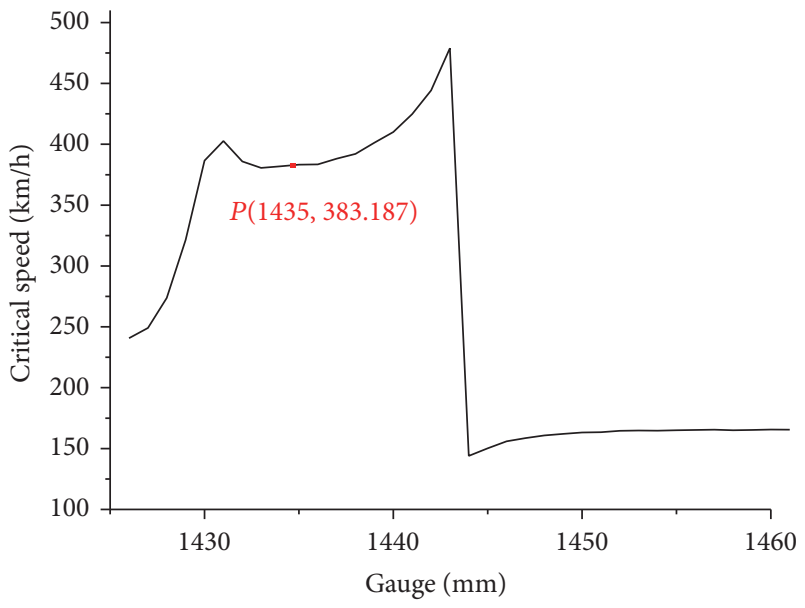

FIGURE 9: Influence of gauge variation on critical speed.

TABLE 4: Ride indexes for vehicles A and B.

\begin{tabular}{lc}
\hline Case & Lateral ride index \\
\hline 1 & 1.55 \\
2 & 2.33 \\
3 & 2.38 \\
4 & 1.53 \\
5 & 1.61 \\
6 & 1.56 \\
\hline
\end{tabular}

Case 4. Vehicle B is running below its critical speed but is excited by track irregularity (both lateral and vertical).

Case 5. Vehicle B is running above its critical speed with initial value as shown in Figure 6.

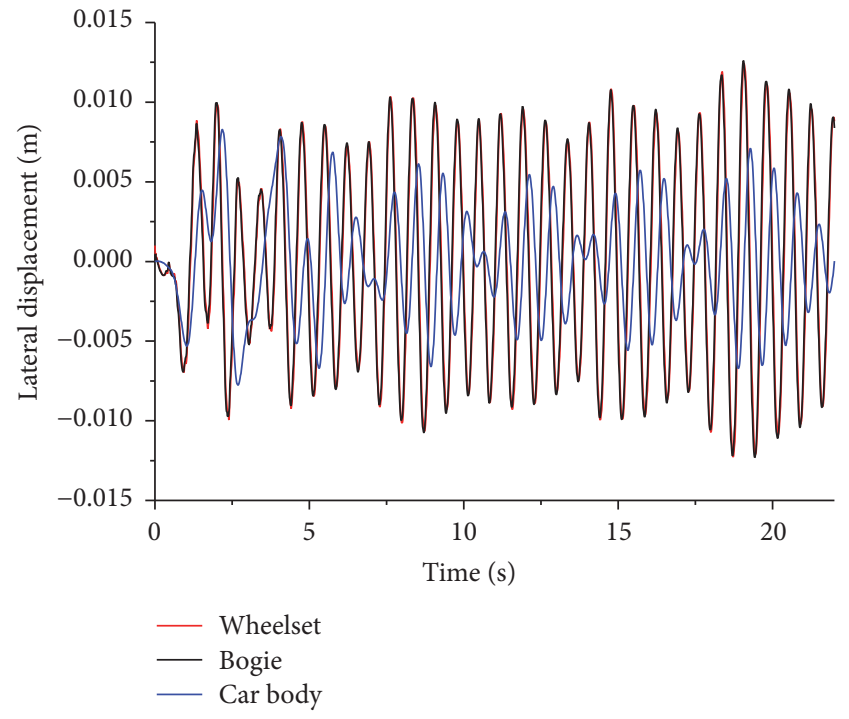

FIgURE 10: Time domain response on condition gauge $=1450 \mathrm{~mm}$ and speed $=300 \mathrm{~km} / \mathrm{h}$.

Case 6. Vehicle B is also running at the same speed as in Case 5 and also is excited by track irregularity as Case 4 .

The lateral ride indices for the three cases of vehicle B are also calculated as shown in Table 4.

From the result, the index for Case 6 is better than Case 5 . We may guess that the time domain response of Case 6 is also random signal adding to periodical solution. But the results in Figure 13 demonstrate that it is not as we expect from Table 4.

From Figure 13, it can be seen that the result of Case 6 is different from that of Case 3 (periodical solution + random signal). The curves of Case 6 seem more like random 


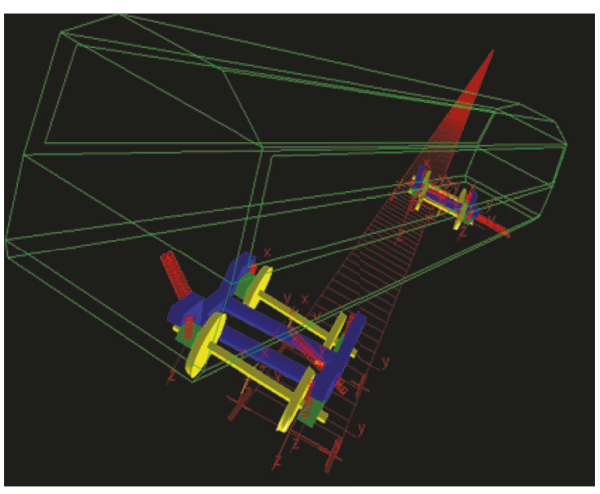

(a) Frequency $=1.6 \mathrm{~Hz}$

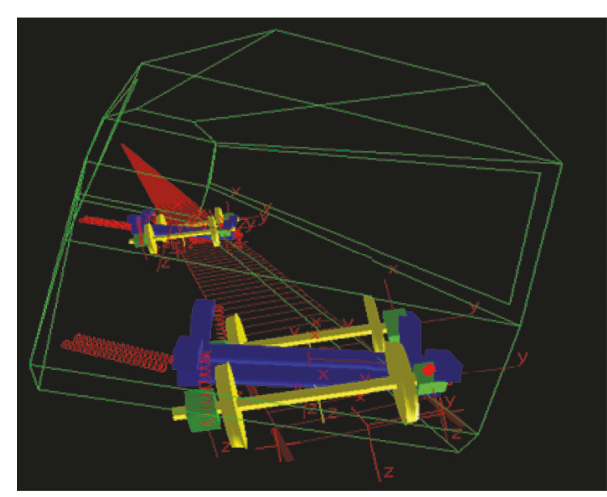

(b) Frequency $=1.8 \mathrm{~Hz}$

FIGURE 11: The unstable modal vectors (solved by Simpack).

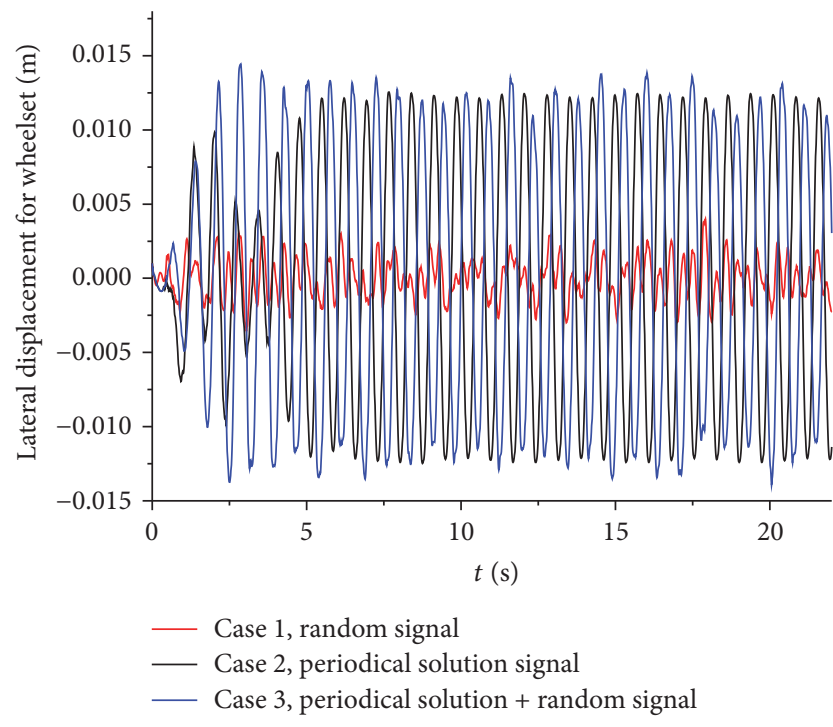

FIGURE 12: Time domain responses for vehicle A.

signals. Considering that the two cases operate under the same condition, only the vehicle type is different, although we know that they have different bifurcation types. Why do Cases 3 and 6 produce different results?

This leads to a problem: how can we predict the behavior of a nonlinear system loss of stability when excited? Here the bogie lateral acceleration for one high line is measured as shown in Figure 14.

It is obvious that the test result is similar to Case 3 but not Case 6. According to the criterion used for online surveillance, specifically the peak value of lateral acceleration on the bogie frame, as defined in the (now invalid) version of UIC 515 [19], the limit value is seen to exceed when the value reaches $8 \mathrm{~m} / \mathrm{s}^{2}$ for more than six consecutive cycles with a frequency of $4-8 \mathrm{~Hz}$, which means the test result for the vehicle is instable. Oldrich Polach did detailed study on bogie stability assessment [20].

However, although we have not measured the instability results online for the vehicle as mentioned in Case 6 because it may have much higher critical speed, it can be supposed

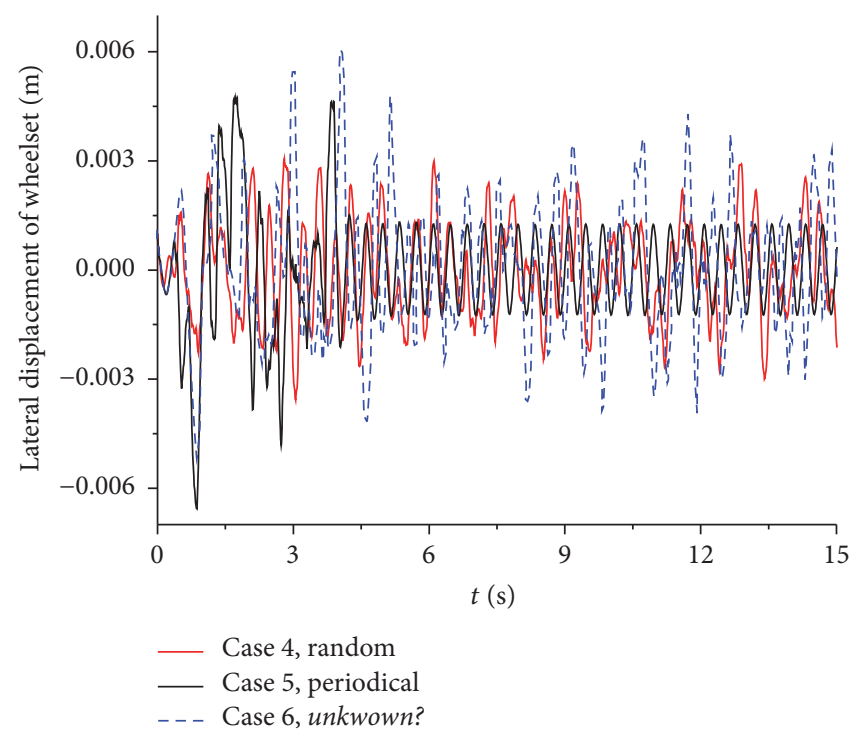

FIgURE 13: Time domain responses for vehicle B.

that the results may have similar wave profile as shown in Figure 13 to Case 6. From Figure 13, Case 5 demonstrates hunting, which may also be tested as instability according to the criterion of UIC 515. Despite the fact that peak value of Case 6 is obviously higher than that of Case 5, according to UIC 515, it does not satisfy the condition that is six consecutive cycles. Therefore, this means that although Case 6 has large disturbance from track irregularity and has worse ride index and while Case 5 has no excitation and has better ride index from Table 4, Case 6 may be tested as stability while Case 5 would be tested as instability. As we know, UIC 515 (1984) is now invalid, but similar standards such as TSI L 84-2008 [21] and one Chinese standard for high-speed vehicle [22] are still used. So the instability test method of measuring the peak value of lateral acceleration and its consecutive cycles on the bogie frame needs to be modified especially for the high-speed vehicle.

From the analysis above, there is no doubt that the external excitation has an influence on the limit cycle, for the stochastic response adding to the periodical solution, 


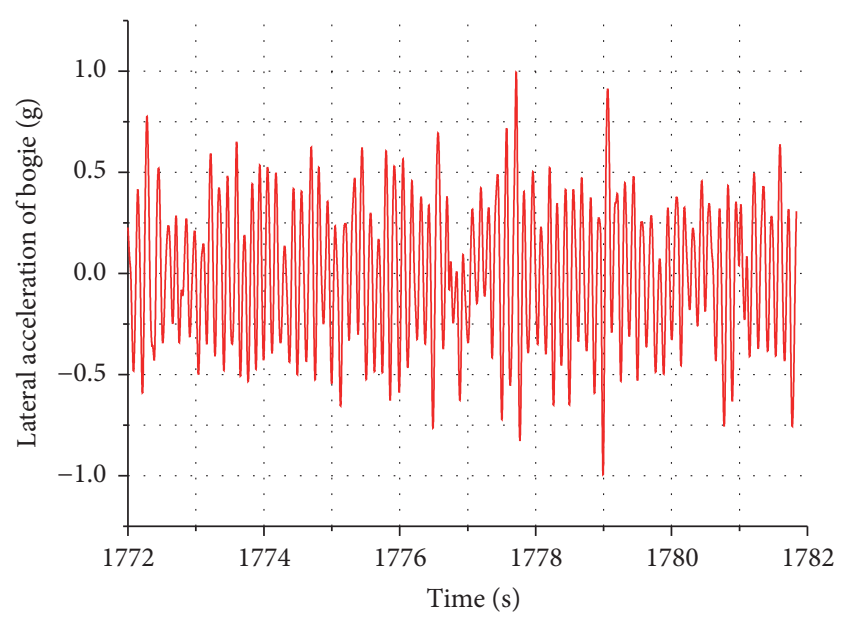

FIGURE 14: Field test result for the bogie lateral acceleration of CRH380B (a section on Beijing-Shanghai line with operation speed $299 \mathrm{~km} / \mathrm{h})$.

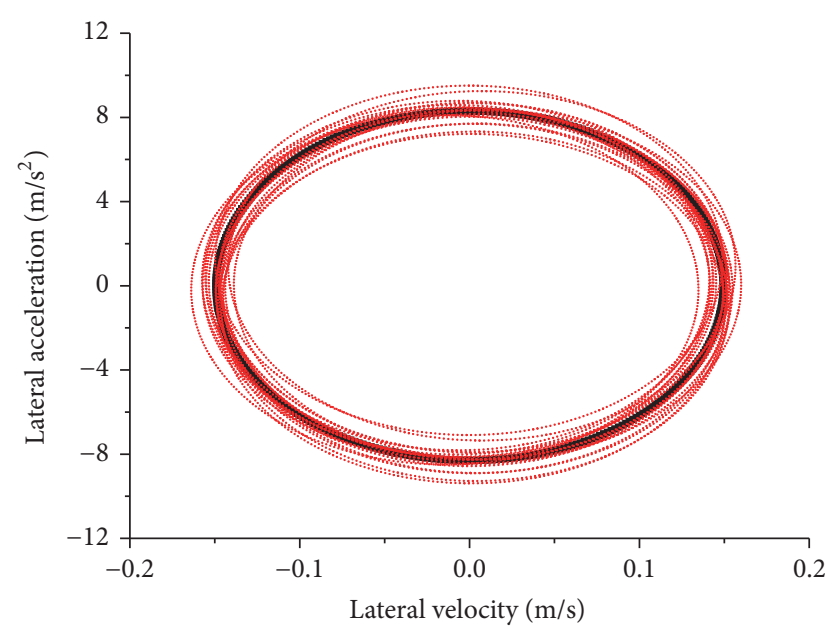

- Limit cycle (without external excitation)

- Limit cycle + stochastic response

Figure 15: Phase plane for one vehicle.

which would make it hard to determine instability (the result in Case 5 compared with that in Case 6). As we know the critical speed is independent of the external excitation. But we should investigate the vehicle stability considering the track irregularity by applying the stochastic stability theory. The latter mainly contains two aspects. One is about parametric excitation. Bigoni studied the critical speed considering that and gave each possible critical speed's probability [23]. The other is about external excitation. This is very difficult in nonlinear stochastic theory; for example, the method of solving the stochastic differential equation (SDE) and the stability theory for SDE have been now only preliminarily studied in mathematics. So far, only Xiang and Zeng's work [24] uses this theory to investigate the derailment problems and Zhang's work gave the primary result that the limit cycle is not an invariant curve but becomes a banding $[25,26]$. Figure 15 will give an illustration.
In Figure 15, the red dot banding is the result of a simple track irregularity simulation as White Gaussian Noise. In fact the actual track excitation may be much more difficult to simulate as stochastic process and to compute. However, evidently from this figure, according to the standards mentioned above, the black results imply instability, but the red results mean uncertainty because it may not meet the condition of more than six consecutive cycles exceeding $8 \mathrm{~m} / \mathrm{s}^{2}$.

\section{Conclusion}

Firstly, the new fast method proposed by Chinese engineers for computing $V_{E}$ instead of $V_{\text {cr }}$ is unscientific and inaccurate through an example of a vehicle with slow converge rate. In addition the ramping way for computing $V_{\text {cr }}$ may also lead to error estimation for nearly one hundred kilometers per hour in types of some supercritical Hopf bifurcation vehicle.

Besides, from the bogie lateral acceleration test and reports on the Beijing-Shanghai high-speed line, the abnormal vibration of nearly $1.8 \mathrm{~Hz}$ which makes passengers uncomfortable is from car body hunting, not bogie hunting, according to the eigenvalue and gauge variation analysis. In the authors' opinion, the cause of this phenomenon may be track gauge increase.

Finally, with preliminary application of the stochastic and nonlinear theory compared with pure nonlinear theory for rail vehicle system, standards such as UIC 515 and TSI L 842008 for assessment bogie instability by measuring the peak value of lateral acceleration need to be modified.

\section{Conflicts of Interest}

The authors declare that there are no conflicts of interest regarding the publication of this paper.

\section{Acknowledgments}

The authors thank Professor Hugh Coolican for polishing the English writing.

\section{References}

[1] M. Ahmadian and S. Yang, "Hopf bifurcation and hunting behavior in a rail wheelset with flange contact," Nonlinear Dynamics, vol. 15, no. 1, pp. 15-30, 1998.

[2] X.-J. Gao, Y.-H. Li, and Y. Yue, "The 'resultant bifurcation diagram' method and its application to bifurcation behaviors of a symmetric railway bogie system," Nonlinear Dynamics, vol. 70, no. 1, pp. 363-380, 2012.

[3] H. Dong, J. Zeng, L. Wu, and H. Dai, "Analysis of the gyroscopic stability of the wheelset," Shock and Vibration, vol. 2014, Article ID 151625, 7 pages, 2014.

[4] W. Zhai, K. Wang, and J. Chen, "Theoretical and experimental investigation on nonlinear lateral dynamical behavior of railway wagon," Chinese Journal of Mechanical Engineering, vol. 44, no. 11, pp. 138-144, 2008.

[5] G. Schupp, "Computational bifurcation analysis of mechanical systems with applications to railway vehicles," in Proceedings of the 18th IAVSD Symposium on Vehicle System Dynamics, The Dynamics of Vehicles on Roads and on Tracks, pp. 458-467, Taylor \& Francis, 2004. 
[6] H. True, "Multiple attractors and critical parameters and how to find them numerically: the right, the wrong and the gambling way," Vehicle System Dynamics, vol. 51, no. 3, pp. 443-459, 2013.

[7] "Research on multiple suspension parametric design method of hunting dynamic theory for CRH2 and CRH3 high speed vehicle," Traction Power Laboratory, CRRC Sifang Co., Ltd., China, 2012.

[8] C. Huang, Study on vibration reduction technology for high speed vehicle [Ph.D. Thesis], Southwest Jiaotong University, China, 2012.

[9] Y. Li, Study on the influence of parameters of high speed vehicle on performance and its application [Ph.D. Thesis], Southwest Jiaotong University, China, 2013.

[10] "Research on the parametric optimization for CRH2 high speed vehicle," Traction Power Laboratory, CRRC Sifang Co., Ltd., China, 2008.

[11] "Research on the parametric optimization for CRH3 high speed vehicle," Traction Power Laboratory, CRRC Changchun Railway Vehicles Co., Ltd., China, 2009.

[12] K. E. Brenan, S. L. Campbell, and L. R. Petzold, Numerical Solution of Initial-Value Problems in Differential-Algebraic Equations, SIAM, Philadelphia, Pa, USA, 2nd edition, 1996.

[13] M. Arnold, "Simulation algorithms in vehicle system dynamics," Department of Mathematics and Computer Science 27, LutherUniversity Halle, 2004.

[14] B. Miao, X. Fang, and X. Fu, Simpack Dynamics Analysis Basic, Southwest Jiaotong University Press, Chengdu, China, 2008.

[15] B. L. Stevens, F. L. Lewis, and E. N. Johnson, Aircraft Control and Simulation: Dynamics, Controls Design, and Autonomous Systems, Wiley-Blackwell, 3rd edition, 2015.

[16] K. Zboiński and M. Dusza, "A simulation study of the track gauge influence on railway vehicle stability in curves," in Proceedings of the First International Conference on Railway Technology: Research, Development and Maintenance, Las Palmas, April 2012.

[17] "Chinese, railway vehicles-specification for evaluation on the dynamic performance and accreditation test," GB5599-85, 1985.

[18] "Guidelines for evaluating passenger comfort in relation to vibration in railway vehicles," UIC code 513, 1994.

[19] "Passenger rolling stock-trailer bogie-running gear-genearl provisions applicable to the components of trailers bogies," UIC code 515, 1984.

[20] O. Polach, "On non-linear methods of bogie stability assessment using computer simulations," Proceedings of the Institution of Mechanical Engineers, Part F: Journal of Rail and Rapid Transit, vol. 220, no. 1, pp. 13-27, 2006.

[21] "Concerning a technical specification for interoperability relating to 'rolling stock' subsystem of the trans-European highspeed rail system," TSI L 84, 2008.

[22] China Academy of Railway Sciences, "Dynamics performance test method and specification for $200 \mathrm{~km} / \mathrm{h}$ or above high speed vehicle," Interim Standard, 2004.

[23] D. Bigoni and H. True, "Sensitivty analysis of the critical speed in railway vehicle dynamics," in Proceedings of the $23 \mathrm{rd}$ International Symposium on IAVSD, Qingdao, China, 2013.

[24] J. Xiang and Q. Y. Zeng, "Mechanism and energy random analysis of train derailment on railway bridges," International Journal of Structural Stability and Dynamics, vol. 9, no. 4, pp. 585-605, 2009.

[25] B. Zhang, J. Zeng, and W. Liu, "Research on stochastic stability and stochastic bifurcation of suspended wheelset," Journal of
Mechanical Science and Technology, vol. 29, no. 8, pp. 3097-3107, 2015.

[26] B. Zhang, Study on stochastic stability and stochastic bifurcation for railway vehicle [Ph.D. Thesis], Southwest Jiaotong University, China, 2016. 


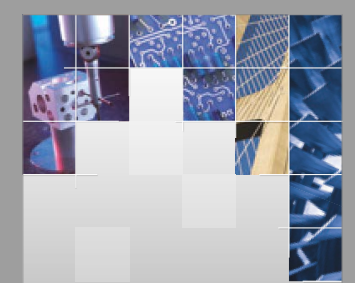

\section{Enfincering}
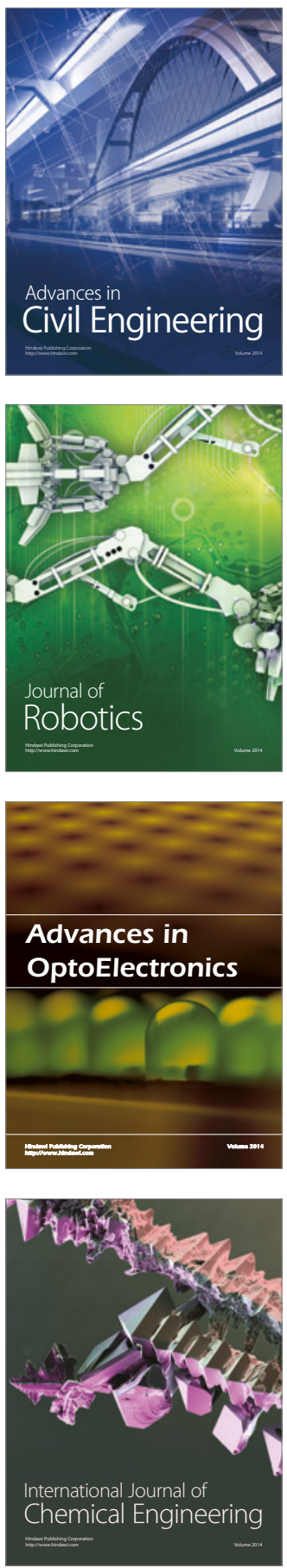

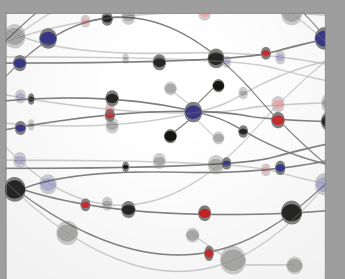

The Scientific World Journal

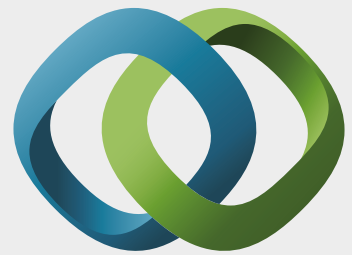

\section{Hindawi}

Submit your manuscripts at

https://www.hindawi.com
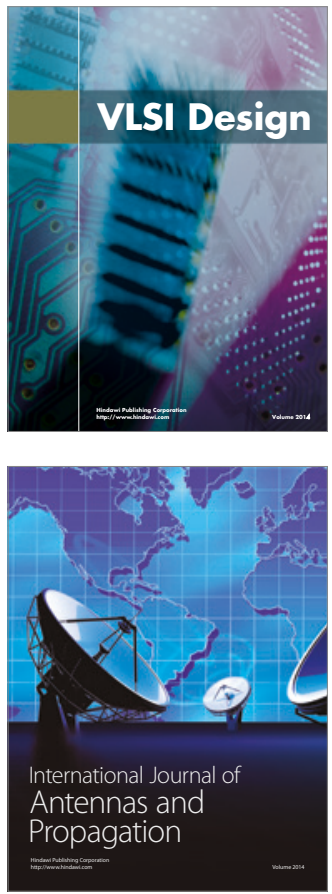

\section{Rotating}

Machinery
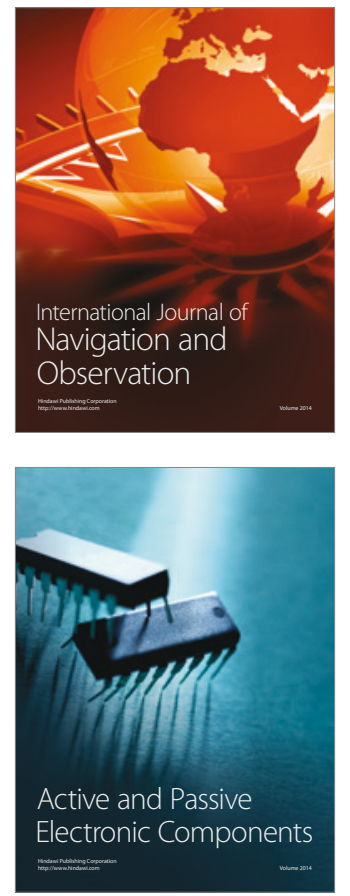
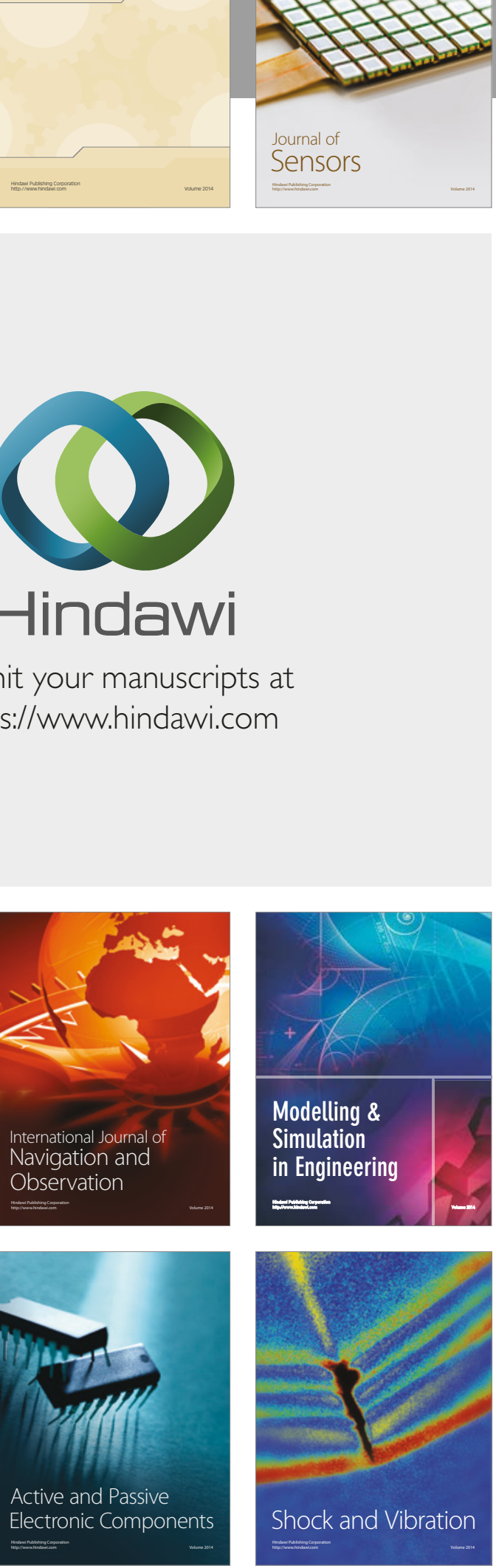
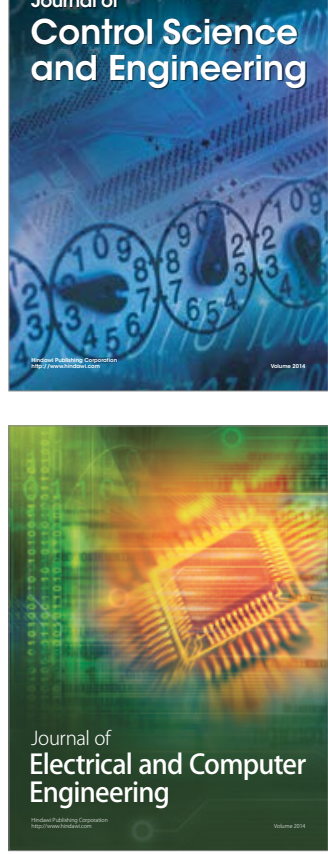

Distributed

Journal of

Control Science

and Engineering
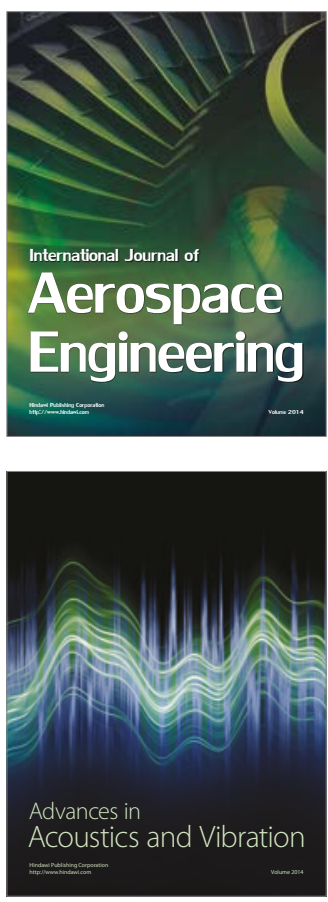

Sensor Networks 